\title{
A Simulation Based Study for the Early Detection of Glaucoma Using Temperature Profiling of Human Eye
}

\author{
Shajib Ghosh, Mamun Rabbani* and A S M Shamsul Arefin \\ Department of Biomedical Physics and Technology, University of Dhaka, Dhaka-1000, Bangladesh
}

(Received : 16 May 2019 ; Accepted : 7 January 2020 )

\begin{abstract}
Glaucoma is one of the leading ophthalmologic disorders worldwide which results in irreversible blindness if left untreated. Although many detection techniques are already in use, they prove to detect glaucoma at a later stage when the disease causes irreversible effects to the optic tissue. This work aims at developing a novel technique to detect the presence and progression of glaucoma at an early stage through temperature profiling of optic tissues by LASER radiation. A 3D CAD model of the real human eye designed in SolidWorks ${ }^{\mathrm{TM}}$ was used and different parameter values were defined for performing thermal simulation in COMSOL Multiphysics ${ }^{\circledR}$ for three distinct LASER point sources: $694.3 \mathrm{~nm}$ Ruby LASER, $1064 \mathrm{~nm}$ Nd:YAG LASER and $1340 \mathrm{~nm}$ Nd:YAP LASER. By analyzing the thermal profile obtained from the simulation, an inverse trend of temperature variation with progression of glaucoma was observed. The effect was most prominently observed in using $694.3 \mathrm{~mm}$ Ruby LASER with no such temperature rise in the eye causing any physiological harm. This work shows the possibility of using temperature profile due to irradiated light on human eye as a novel biomarker for the early detection of glaucoma.
\end{abstract}

Keywords: Glaucoma, temperature profiling, thermal simulation, LASER irradiation.

\section{Introduction}

Amongst the various physiological reasons causing blindness, Glaucoma is becoming a major cause worldwide. According to WHO, glaucoma is the second leading cause of blindness ${ }^{1}$. The underlying threat to glaucoma related blindness is that it is irreversible. Glaucoma is a collective term for a group of eye conditions where the optic nerve as presented in Fig. 1 is damaged due to elevated intraocular pressure (IOP). In its early stages, glaucoma usually has no symptoms or very little indications. By the time a person can notice any problem with sight, the disease may have progressed to a point of irreversible vision loss. Therefore, early detection of glaucoma is very important.

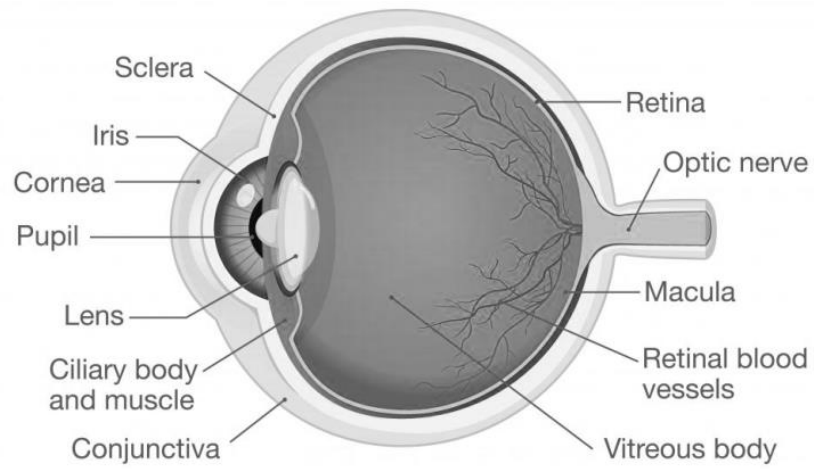

Fig. 1. Anatomy of the Human Eye ${ }^{2}$

Although the pathogenesis of glaucoma is not fully understood, the level of intraocular pressure is related to retinal ganglion cell death. The balance between secretion of aqueous humour by the ciliary body and its drainage through two independent pathways - the trabecular meshwork and uveoscleral outflow pathway - determines the intraocular pressure.

*Author for correspondence. e-mail: mamunrabbani@du.ac.bd
Glaucoma can be classified into two broad categories: open-angle glaucoma and angle closure glaucoma. In patients with open-angle glaucoma, there is increased resistance to aqueous humour outflow through the trabecular meshwork. In contrast, the access to the drainage pathways is obstructed typically by the iris in patients with angle-closure glaucoma ${ }^{3}$.

The tonometry test can take measurements of IOP very quickly. Although it is not effective in early detection of glaucoma as half of the new glaucoma cases do not exhibit elevated $\mathrm{IOP}^{4}$ while in some cases people with glaucomatous eye exhibit regular $\mathrm{IOP}^{5}$. Ophthalmoscopy is a diagnostic procedure where the doctor examines the optic nerve by diluting the pupil ${ }^{5}$. This process is a rather subjective one and the final decision is done based on some more tests like Perimetry and Gonioscopy. Perimetry maps the complete field of vision and helps in determining whether a human eye is affected by glaucoma 5 . Gonioscopy diagnoses the angle between the iris and the cornea and determines whether it is open and wide or closed and narrow ${ }^{5}$. Pachymetry measures the thickness of the cornea and gives an idea about the IOP of the eye as the thickness of the cornea is correlated to the $\mathrm{IOP}^{5}$. Although there are many tests, quite a few of them are subjective and dependent on the physician's capability of analyzing the results. Besides, these tests involve use of tranquilizing drugs to numb the eye which might cause side-effects in patients. And most importantly, none of them seem to be effective in detecting the disease at its early stage.

Many research works are performed on thermal distribution analysis in the human eye. Mirnezami SA et al. studied the temperature distribution by simulating human eye model under 1064 nm Nd:YAG LASER, 193 nm ArF Excimer LASER and $1340 \mathrm{~nm}$ Nd:YAP LASER radiation ${ }^{6}$. Claudia Fabianiet al. in their research showed a clinical 
thermographic analysis of the relationship between corneal individuals ${ }^{7}$. Gabelt\& Kaufman showed the relation between age and progression of glaucoma ${ }^{8}$. Based on these findings, temperature variation of the eye at various stages of progression of glaucoma can be used as a biomarker for early detection.

This work attempted to establish a new approach for early detection of glaucoma based on temperature profiling of the human eye.During the progression of glaucoma, it is expected that the IOP will increase in linear pattern with increasing accumulation of aqueous humor. Hence, a glaucomatous eye will have a different temperature profile than a normal eye if irradiated with an external light source at various stages of progression. Computational modelling of human eye was developed keeping in mind the underlying physiology of human eye ${ }^{9-10}$.Finally, temperature profiling was examined to find out any relationship pertinent to early glaucoma detection.

\section{Methodology}

This work is based on temperature profiling of human eye due to external radiation by LASER sources. If the eye is irradiated with an external LASER source, various regions of the eye will show different temperatures based on their constituents. Due to glaucoma, resistance in the trabecular meshwork increases causing an accumulation of aqueous humour in the optical chamber. Hence, irradiated LASER will show a different temperature profiling of the regions in case of glaucoma. Since the accumulation of aqueous humour is related to increase in IOP, temperature profiling through irradiation can be linked with changes in IOP and therefore with glaucoma.

Some assumptions were made in this work to develop the modelling. The volume of the anterior chamber is assumed not to change significantly with accumulation of aqueous humour. The progression of glaucoma is assumed to be linear, i.e. IOP increases linearly with accumulation of aqueous humour in the anterior chamber.

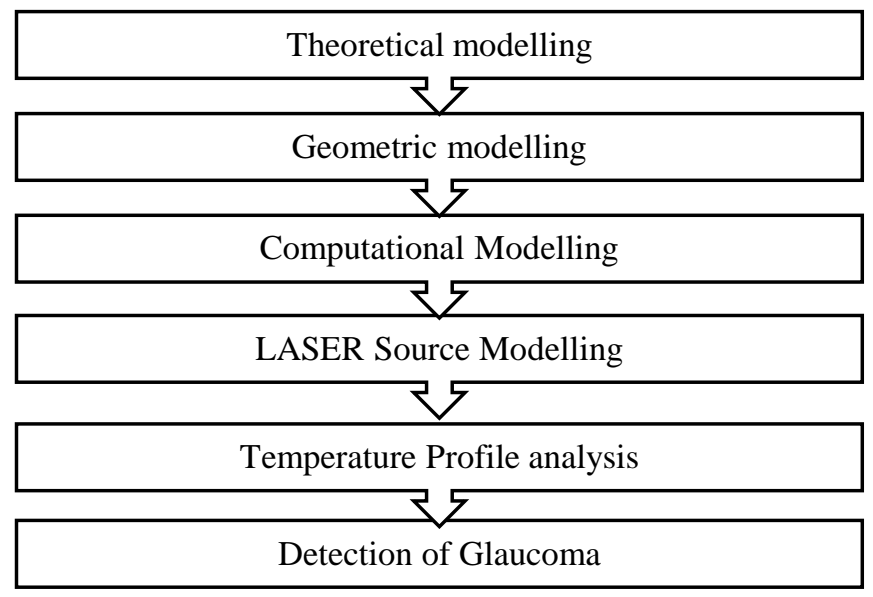

Fig. 2. Work flow of the study
Based on these points, a work flow was followed in executing this work as shown in Fig.2. A theoretical model was developed initially based on established studies. Sequentially, a geometric model was developed for the human eye keeping in mind the basic anatomy. Furthermore, a computational model was established based on the geometry. The LASERS under considerations were modelled. Based on these modelling, a temperature profile was generated and analyzed to detect glaucoma.

\section{(a) Theoretical Modelling}

The theoretical model underlying this work has been defined from the basic principle of thermodynamics. This model can be described as follows

The variation in temperature is inversely proportional to the amount of fluid present in the anterior chamber of the human eye or the mass of the aqueous humour provided that the energy (or power) of the heat source (e.g.LASER source) remains constant.

This model is supported by the definition of Specific heat capacity. According to the definition,

$$
Q=m S \Delta T
$$

where, $\mathrm{Q}=$ heat energy, $\mathrm{m}=$ mass of substance, $\mathrm{S}=$ Specific heat capacity of substance and $\Delta T=$ temperature variation.

Rearranging equation (1), we get

$$
\Delta T=Q / m S
$$

Equation (2) suggests that if the applied heat energy is kept constant, then the temperature variation due to heat is inversely proportional to the mass of the substance as the specific heat is always constant. This can be shown as

$$
\Delta T \propto 1 / m
$$

This relation is applied in the case of glaucoma affected eye. With the progression of glaucoma, aqueous humour starts to accumulate in the eye, hence that mass of aqueous humour increases. When the eye is heated with the same energy at various stages of glaucoma, an inverse relation is expected to be found with the temperature.

The pressure exerted by a fluid in any volume can be expressed by the relation ${ }^{11}$

$$
\begin{gathered}
P=\rho g h \\
\text { or, } P=\frac{m}{V} g h
\end{gathered}
$$

where, $\mathrm{P}$ is the Static fluid pressure, $\mathrm{m}$ is the mass of the fluid, V is the volume of the chamber the fluid is contained, $\mathrm{g}$ is the gravitational acceleration and $\mathrm{h}$ is the depth of the volume. If the volume and depth are considered constant, (4) can be written as

$$
P \propto m
$$


Combining the relations (3) and (5), we get

$$
\Delta T \propto 1 / P
$$

If we consider the static fluid to be the aqueous humour and the enclosed volume to be the chamber of the eye, (6) gives a relation between temperature and static pressure of the aqueous humour.

From the works of Paul E. Miller ${ }^{9}$, a mathematical relation regarding IOP and corresponding aqueous humour statistics for normal and glaucomatous eyes can be found. The relation between IOP and various parameters of IOP generation and propagation can be found from the equation $^{9}$

$$
P=\frac{F}{C}+P_{e}
$$

where, $\mathrm{P}$ is the Intra Ocular Pressure (IOP), $\mathrm{F}$ is the rate of aqueous formation, $\mathrm{C}$ is the facility of aqueous outflow and $\mathrm{P}_{\mathrm{e}}$ is the episcleral venous pressure.

The rate of aqueous humour formation for both normal and glaucomatous eyes is $2 \mu \mathrm{L} / \mathrm{min}$. But aqueous outflow capacity for normal eye is $0.28 \mu \mathrm{L} / \mathrm{min} / \mathrm{mm} \mathrm{Hg}$ and for glaucomatous eye is $0.18 \mu \mathrm{L} / \mathrm{min} / \mathrm{mm} \mathrm{Hg}$. The episcleral venous pressure ranges from $5-15 \mathrm{~mm} \mathrm{Hg}$. In this work, the average episcleral venous pressure was considered as 10 $\mathrm{mm} \mathrm{Hg}$.

From (7), the IOP for normal eye and glaucomatous eye can be calculated as follows

$$
\begin{gathered}
P_{\text {normal }}=\frac{F}{C_{\text {normal }}}+P_{e} \\
P_{\text {glaucoma }}=\frac{F}{C_{\text {glaucoma }}}+P_{e}
\end{gathered}
$$

From (5), we can write

$$
\begin{aligned}
P_{\text {normal }} & \propto m_{\text {normal }} \\
P_{\text {glaucoma }} & \propto m_{\text {glaucoma }}
\end{aligned}
$$

Taking the ratio of (11) to (10), we get the following

$$
\begin{gathered}
\frac{P_{\text {glaucoma }}}{P_{\text {normal }}}=\frac{m_{\text {glaucoma }}}{m_{\text {normal }}} \\
\text { or, } m_{\text {glaucoma }}=\frac{P_{\text {glaucoma }}}{P_{\text {normal }}} \times m_{\text {normal }}
\end{gathered}
$$

Assuming linear distribution, the progression of glaucoma has been divided into 11 stages where stage-1 is the initial normal condition of the eye and stage-11 is the final state of glaucoma affected eye. Using (9), the IOPs for various stages of glaucoma wer ededuced. From (12) the mass of aqueous humour in various stages of glaucoma has been determined. The calculated mass of aqueous humour at various stages of glaucoma has been given in Table 1.
Table 1. Calculated value of aqueous humour at various stages of Glaucoma

\begin{tabular}{|c|c|}
\hline Stages of the progression of glaucoma & $\begin{array}{c}\text { Aqueous } \\
\text { humour } \\
(\mathrm{mg})\end{array}$ \\
\hline \hline Stage -1 : & 0.231 \\
\hline Stage -2 & 0.235 \\
\hline Stage -3 & 0.238 \\
\hline Stage -4 & 0.243 \\
\hline Stage -5 & 0.247 \\
\hline Stage $-6:$ & 0.252 \\
\hline Medium progression of glaucoma & 0.257 \\
\hline Stage -7 & 0.263 \\
\hline Stage -8 & 0.269 \\
\hline Stage -9 & 0.276 \\
\hline Stage -10 & 0.284 \\
\hline Stage $-11:$ & \\
\hline Glaucoma condition (final stage) & \\
\hline
\end{tabular}

\section{(b) Geometrical Modelling}

For this study, freely available 3D CAD design from GrabCAD model library has been used $^{12}$. The design compatible for the simulation was made in COMSOL Multiphysics ${ }^{\circledR}$.The parameters associated with each tissue were defined with the values regarding the thermo-physical and optical properties. The 3D model of the human eye is shown in Fig.3.

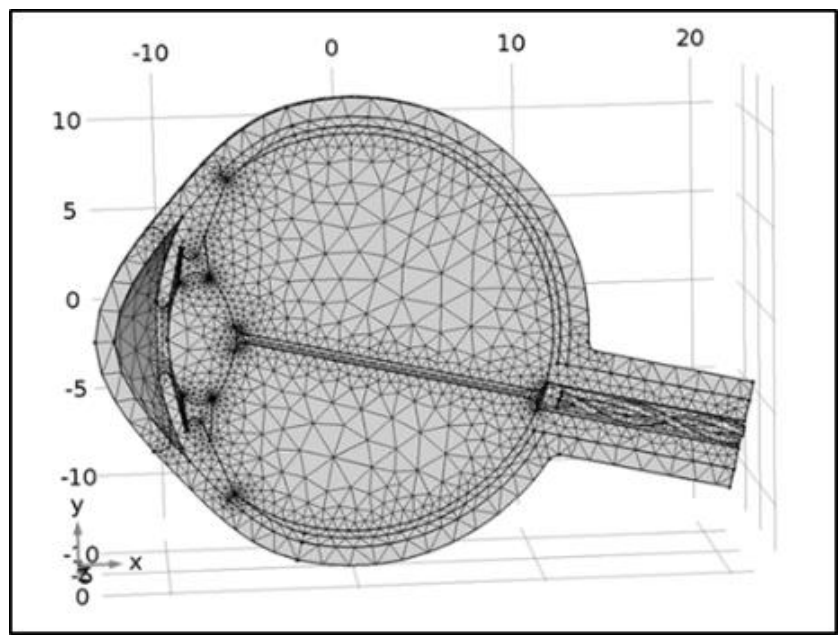

Fig. 3. 3D geometric model and meshing of the human eye

\section{(c) Computational Modelling}

The temperature distribution inside the human eye can be determined by solving the Pennes' bioheat transfer equation $^{13}$.The Pennes' equation represents the energy balance between conductive heat transfer, heat generated by 
the metabolic processes, and the heating or cooling effects due to the flow of arterial blood ${ }^{13}$ :

$$
\rho c \frac{\partial T}{\partial t}=\nabla(\mathrm{k} \nabla \mathrm{T})+w_{b} c_{b}\left(T_{a}-T\right)+q_{m}
$$

where, $\rho=$ Density, $\mathrm{c}=$ Specific heat, $\mathrm{k}=$ Tissue thermal conductivity, $\mathrm{w}_{\mathrm{b}}=$ Mass flow rate of blood per unit volume of tissue, $\mathrm{c}_{\mathrm{b}}=$ Blood's specific Heat, $\mathrm{q}_{\mathrm{m}}=$ Metabolic heat generation per unit volume, $\mathrm{T}_{\mathrm{a}}=$ Temperature of arterial blood $(\mathrm{K}), \mathrm{T}=$ Temperature rise above the ambient level (K), $\frac{\partial T}{\partial t}=$ Rate of temperature rise $(\mathrm{K} / \mathrm{s})$.

Analytical solution of the Pennes' bio-heat transfer equation is limited to a few simple geometries with high degree of symmetry, but using the Finite Element Method we were able to solve problems on complex geometry, such as human eye ${ }^{6}$.For simplicity, some tissue parameters were merged together due to similarities in their thermal properties. The material properties of various domains of the 3D eye model for the simulation are shown in Table 2 .

Table 2. Material properties of various domains used in the 3D eye model simulation ${ }^{13}$

\begin{tabular}{|l|c|c|c|}
\hline Parts of eye & $\begin{array}{c}\text { Heat Capacity at } \\
\text { constant } \\
\text { pressure } \\
\left(\mathrm{J} \mathrm{kg}^{-1} \mathrm{~K}^{-1}\right)\end{array}$ & $\begin{array}{c}\text { Density } \\
\left(\mathrm{Kg} \mathrm{m}^{-3}\right)\end{array}$ & $\begin{array}{c}\text { Thermal } \\
\text { Conductivity } \\
\left(\mathrm{W} \mathrm{m}^{-1} \mathrm{~K}^{-1}\right)\end{array}$ \\
\hline $\begin{array}{l}\text { Cornea } \\
\text { \&Aqueous } \\
\text { Humour }\end{array}$ & 4178 & 1050 & 0.58 \\
\hline Lens & 3000 & 1000 & 0.40 \\
\hline Ciliary Body & 3421 & 1090 & 0.49 \\
\hline Sclera & 4178 & 1000 & 0.58 \\
\hline Iris and Pupil & 3650 & 1100 & 1.68 \\
\hline $\begin{array}{l}\text { Vitreous } \\
\text { Humour }\end{array}$ & 3997 & 1000 & 0.594 \\
\hline Choroid & 4178 & 1050 & 0.60 \\
\hline $\begin{array}{l}\text { Retina and } \\
\text { Optic Nerve }\end{array}$ & 3680 & 1000 & 0.565 \\
\hline $\begin{array}{l}\text { Retinal Blood } \\
\text { Vessels }\end{array}$ & 3600 & 1050 & 0.53 \\
\hline
\end{tabular}

\section{(d) LASER Source Modelling}

In ophthalmology, the LASER sources that are commonly used include Neodymium-doped Yttrium Aluminum Garnet(Nd:YAG)LASER, Neodymium-doped Yttrium Aluminum Perovskite (Nd:YAP) LASER, Argon Fluoride (ArF) Excimer LASER, Ruby LASER, Diode LASER etc.
For this study, three LASERs were considered: Nd:YAG LASER, Nd:YAP LASER, Ruby LASER.Nd:YAG LASER is used in Cataract removal, Vitrectomy, Corneal transplant, glaucoma surgery ${ }^{14}$. Nd:YAP LASER is used in dentistry ${ }^{15}$ while Ruby LASER is used in skin treatment ${ }^{16}$.

In order to irradiate the human eye, the LASER source should be placed close to the cornea. In this work, the outermost point of the cornea is assumed to be the position of the point source LASER. Positioning the source in vicinity to the cornea reduces the possibility of LASER power attenuation due to atmospheric scattering. The parameters associated with each LASER point source are defined in COMSOL Multiphysics ${ }^{\circledR}$. The absorption coefficients for different parts of the 3D eye model for three different LASER sources are based on various literature ${ }^{13,17}$ and are summarized in Table 3.

Table 3. Absorption coefficients of different parts of the human eye for three LASER sources (Ruby LASER, Nd:YAG LASER, Nd:YAP LASER) $)^{13,17}$

\begin{tabular}{|c|c|c|c|}
\hline \multirow{2}{*}{$\begin{array}{c}\text { Parts of the } \\
\text { human eye }\end{array}$} & \multicolumn{3}{|c|}{$\begin{array}{c}\text { Absorption Coefficient } \\
\left(\mathrm{m}^{-1}\right)\end{array}$} \\
\cline { 2 - 4 } & $\begin{array}{c}\text { Ruby } \\
\text { LASER } \\
\text { Wavelength: } \\
694.3 \mathrm{~nm} \\
\text { LASER power: } \\
2.4 \mathrm{~W}\end{array}$ & $\begin{array}{c}\text { Nd: YAG } \\
\text { LASER } \\
\text { Wavelength: } \\
1064 \mathrm{~nm} \\
\text { LASER } \\
\text { Power: 5 W }\end{array}$ & $\begin{array}{c}\text { Nd: YAP } \\
\text { LASER } \\
\text { Wavelength: } \\
1340 \text { nm } \\
\text { LASER } \\
\text { Power: } 10 \\
\text { W }\end{array}$ \\
\hline $\begin{array}{c}\text { Cornea and } \\
\text { Aqueous } \\
\text { Humour }\end{array}$ & $12400^{*}$ & $11300^{*}$ & $24000^{*}$ \\
\hline Lens & 950 & 4350 & 23500 \\
\hline Ciliary Body & 8167 & 4250 & 22200 \\
\hline Sclera & 35855 & 63450 & 34000 \\
\hline Iris and Pupil & $8167^{*}$ & $4250^{*}$ & $22200^{*}$ \\
\hline $\begin{array}{c}\text { Vitreous } \\
\text { Humour }\end{array}$ & 200 & 2000 & 22400 \\
\hline Choroid & 1684700 & 661500 & 22200 \\
\hline $\begin{array}{c}\text { Retina and } \\
\text { Optic Nerve }\end{array}$ & $4400000^{*}$ & $1000000^{*}$ & $115000^{*}$ \\
\hline $\begin{array}{c}\text { Retinal } \\
\text { Blood } \\
\text { Vessels }\end{array}$ & 4400000 & 1000000 & 115000 \\
\hline
\end{tabular}

*The most significant values are considered 


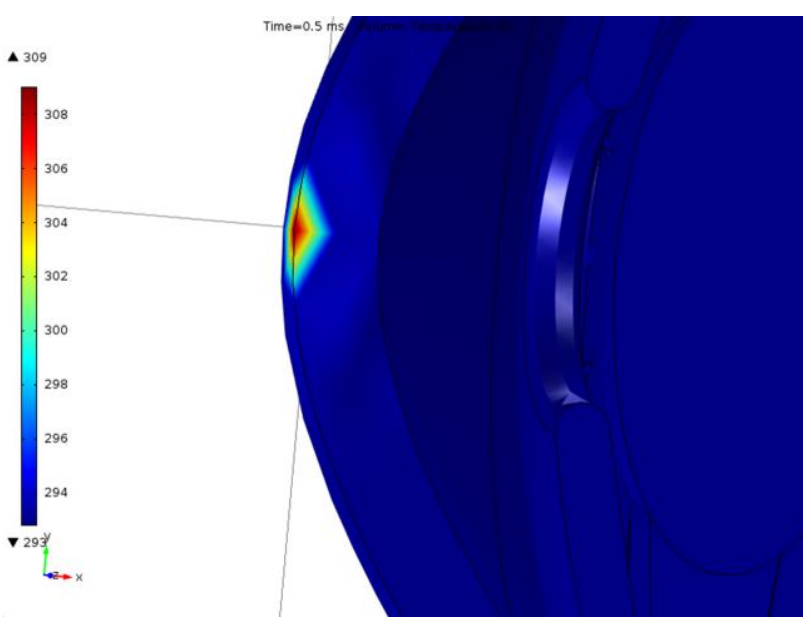

(a)

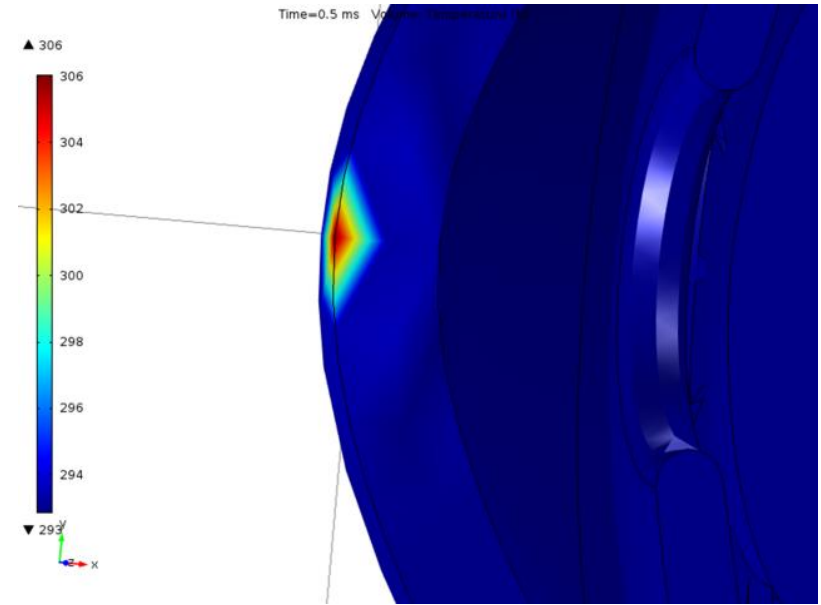

(b)

Fig. 4. Simulation of 3D eye model for temperature profile, zoomed in the corneal region for Ruby laser source (pulse $0.5 \mathrm{~ms}$ ) (a) Normal Eye (b) Glaucoma affected Eye

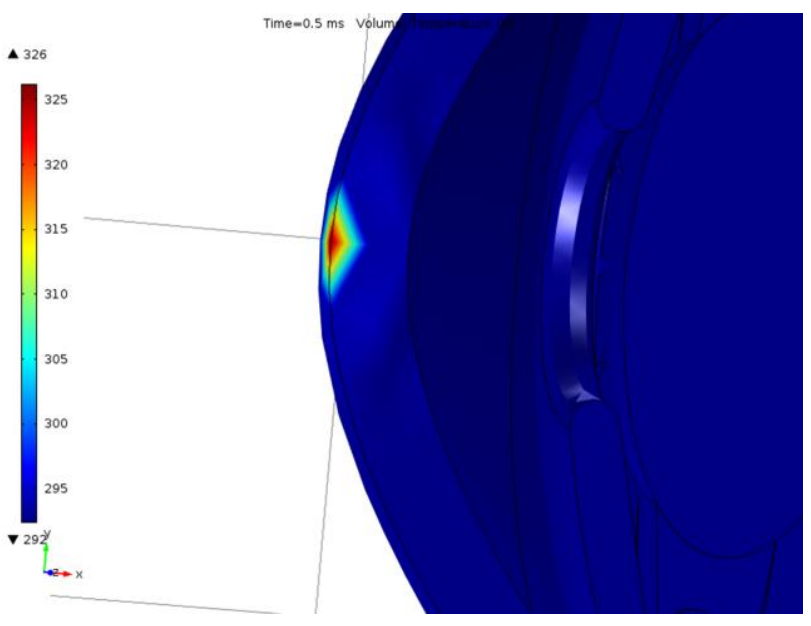

(a)

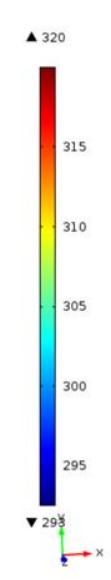

(b)

Fig. 5. Simulation of 3D eye model for temperature profile, zoomed in the corneal region for Nd:YAG laser source(pulse $0.5 \mathrm{~ms}$ ) (a) Normal Eye (b) Glaucoma affected Eye

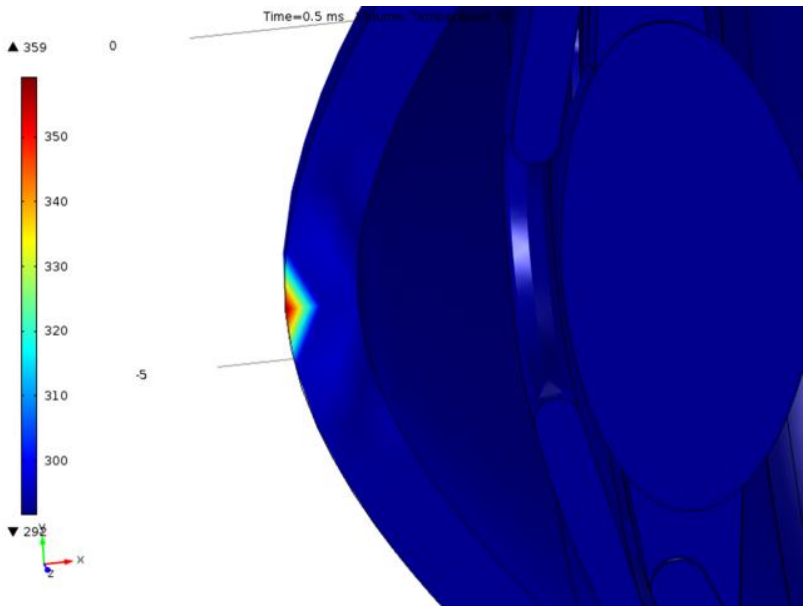

(a)

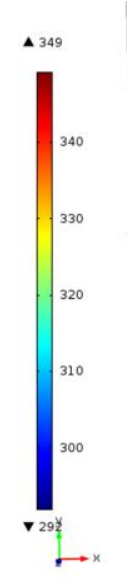

(b)

Fig. 6. Simulation of 3D eye model for temperature profile, zoomed in the corneal region for Nd:YAP laser source(pulse $0.5 \mathrm{~ms}$ ) (a) Normal Eye (b) Glaucoma affected Eye 


\section{Results and Discussion}

The pulse duration of most of the photo-thermal devices used in clinical practice is between $0.5 \mathrm{~ms}$ to $1.0 \mathrm{~ms}^{18}$. A total number of 66 simulations with the three LASER sources were done with the pulse duration of $0.5 \mathrm{~ms}$ and $1.0 \mathrm{~ms}$. Longer pulse duration sources are used in tumor ablation but seldom used in ophthalmologic purposes. So pulse durations above $1.0 \mathrm{~ms}$ are avoided $^{18}$. The $3 \mathrm{D}$ simulation figures for temperature profiling for three different sources are shown in Fig.4, Fig.5 and Fig.6.

The temperature profiles of the three sources at different stages of glaucoma for $0.5 \mathrm{~ms}$ pulse duration is shown in Fig.7 and for $1.0 \mathrm{~ms}$ pulse duration is shown in Fig.8. The graphs show plots of temperature variation with progression of glaucoma. The amount of aqueous humour is divided in 11 stages assuming linear progression of glaucoma. These stages are shown in the horizontal axes of the graphs. The vertical graphs show the variation of temperature in Kelvin unit. The principle findings of this work are stated below.

An inverse profile of temperature is seen with progression of glaucoma. As with the progression of glaucoma, the mass of the aqueous humour accumulated in the optic chamber increases, temperature is expected to fall if irradiated with the same energy source of a fixed pulse duration, which is justified from the relation derived in equation (3). Although the change in quantity of aqueous humor is very subtle at various stages of glaucoma, there is a significant variation in the temperature profiles in these stages of progression.

For a specific stage in glaucoma and for a specific LASER source, temperature in the optic tissue rises more for longer pulse duration. This is evident from comparing Fig.7 and Fig.8. It is also prominent that the temperature variation due to irradiated light is high for higher pulse duration of LASER source.Unfortunately, the higher temperature ranges found for longer pulse durations pose threats for irreversible tissue damage.

For $1064 \mathrm{~nm} \mathrm{Nd:YAG} \mathrm{LASER,} \mathrm{the} \mathrm{range} \mathrm{of} \mathrm{temperature}$ variation is $351.16 \mathrm{~K}$ to $343.39 \mathrm{~K}$ for $0.5 \mathrm{~ms}$ pulse duration and $406.45 \mathrm{~K}$ to $391.59 \mathrm{~K}$ for $1.0 \mathrm{mspulse}$ duration. Collagen denaturation, photo-disruption may occur for using this source. $^{19,20}$

For $1340 \mathrm{~nm} \mathrm{Nd:YAP} \mathrm{LASER,} \mathrm{the} \mathrm{range} \mathrm{of} \mathrm{temperature}$ variation is $359.07 \mathrm{~K}$ to $346.7 \mathrm{~K}$ for $0.5 \mathrm{~ms}$ pulse duration and

\section{Temperature vs. Mass of Aqueous Humor Curve for Progressive Glaucoma}

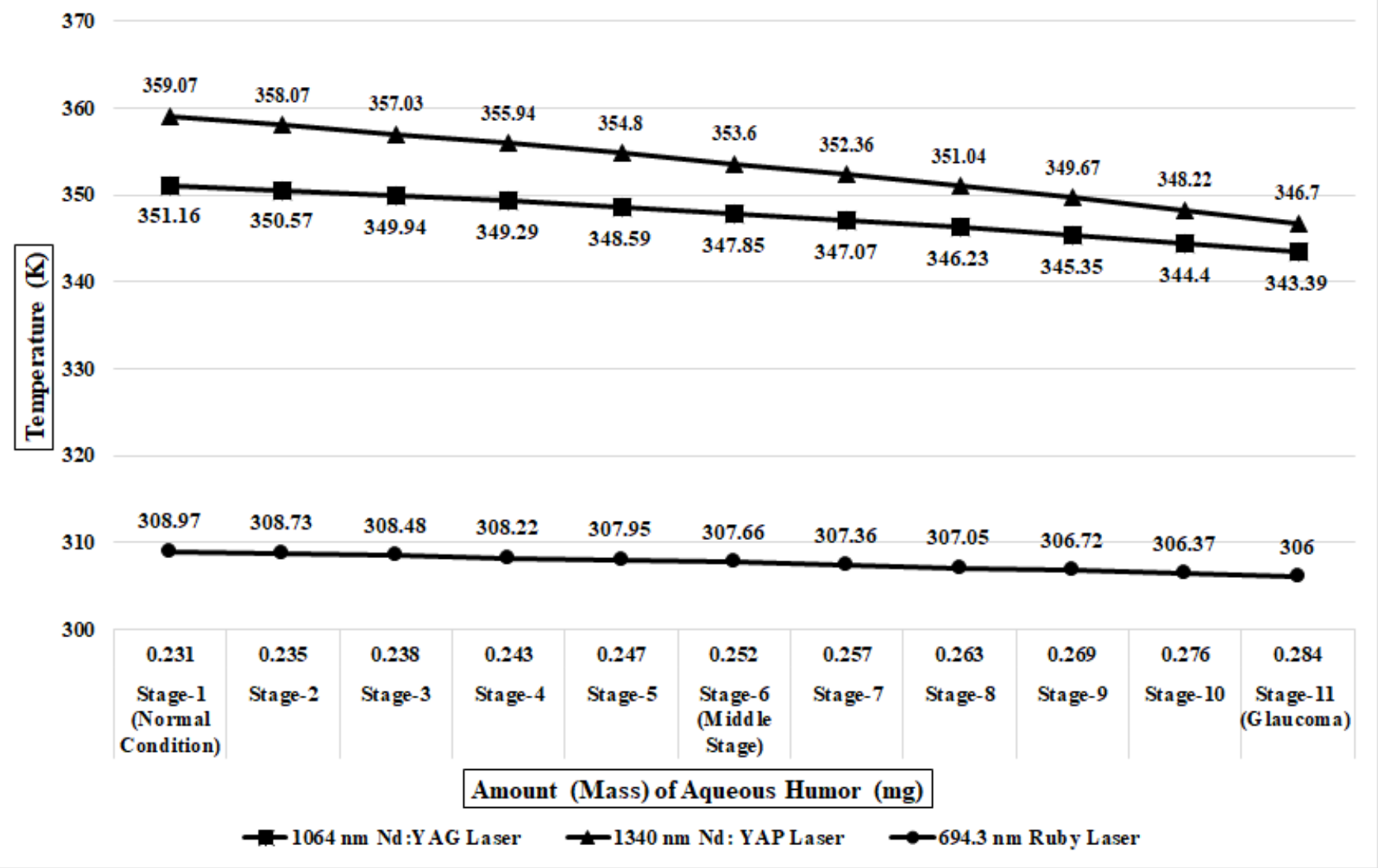

Fig. 7. Temperature vs. mass of aqueous humour with the progression of glaucoma for different LASER sources (pulse duration : $0.5 \mathrm{ms)}$ 


\section{Temperature vs. Mass of Aqueous Humor Curve for Progressive Glaucoma}

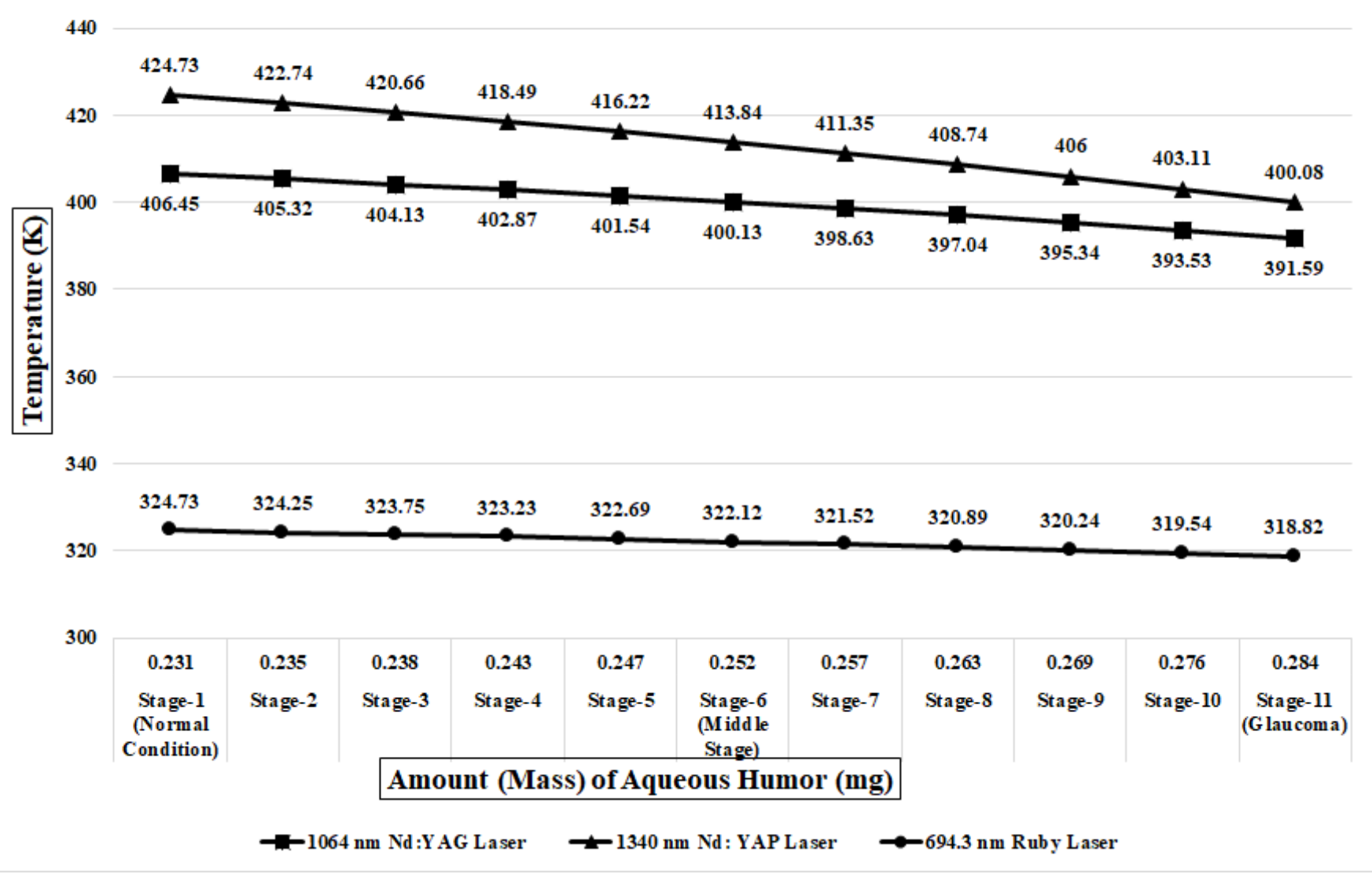

Fig. 8. Temperature vs. mass of aqueous humour with the progression of glaucoma for different LASER sources (pulse duration : $1.0 \mathrm{ms)}$

424.73K to $400.08 \mathrm{~K}$ for $1.0 \mathrm{~ms}$ pulse duration. Dehydration may occur for using this source. 19,20

For $694.3 \mathrm{~nm}$ Ruby LASER, the range of temperature variation is $308.97 \mathrm{~K}$ to $306 \mathrm{~K}$ for $0.5 \mathrm{~ms}$ pulse duration and $324.73 \mathrm{~K}$ to $318.82 \mathrm{~K}$ for $1.0 \mathrm{~ms}$ pulse duration. The average temperature of the human eye is $306.97 \mathrm{~K}$ to $308.56 \mathrm{~K}^{21}$.It is expected that no harm or significant physical change occurs for $0.5 \mathrm{~ms}$ pulse duration, only the temperature of the optic tissues increases. Hence it can be concluded that Ruby LASER is preferable over other sources for pulse duration of $0.5 \mathrm{~ms}$.

From the results, it can be deduced that temperature variation can be defined as a potential biomarker for the early detection of glaucoma. With relevance to the proposed hypothesis, an inverse trend in temperature variation with the progression of glaucoma due to irradiated light from LASER sources is observed in the human eye especially in the cornea and aqueous humour region.By means of measuring temperature at various parts of the optic tissue, this method could be used to determine the presence and progression of glaucoma. Moreover this technique is based on light-tissue interaction for a very short period of time resulting in less patient discomfort. Light interaction is non-invasive in nature which gives this process an upper hand over other techniques. As the interaction time is very short, anaesthetics or immobilization drugs are not required unlike the regular techniques like Ophthalmoscopy, Perimetry or Pachymetry. Besides, this technique is capable of detecting glaucoma at various stages of progression which is difficult in other methods of practice. Hence this technique proves to be a novel one in early detection of glaucoma in human eye.

\section{Conclusion}

The principle objective of this work was to establish a novel approach in early detection of glaucoma in human eye. All the relevant simulations were performed by creating $3 \mathrm{D}$ models of human eye and light sources. The simulated results were analyzed and an inverse relation of temperature variation due to irradiated light with progression of glaucoma was obtained which is justified by the theoretical relation made between temperature and the mass of aqueous humour. In addition, this work proposes Ruby LASER as a safe activation source for temperature profiling. 
Temperature variation due to irradiated light can be used as the parameter for detecting glaucoma at an early stage. Therefore, irreversible blindness and other complexities caused by glaucoma can be avoided. Treatment planning for glaucoma will be easier.

Joining this finding with non-invasive thermal imaging of eye (IR Thermography) can be a complete diagnostic procedure in detection of glaucoma in early stages.This method can be used in other ophthalmological disorders, e.g. Age-related Macular Degeneration (AMD), Diabetic Retinopathy, Cataracts and Optical Pathway Glioma etc. Hence it can be concluded that this method, if successfully established, can be considered as a benchmark detection technique for the diagnosis of Glaucoma and other ophthalmologic disorders.

\section{References}

1. Resnikoff S., Pascolini D., Etya'ale D.,Kocur I., Pararajasegaram R., Pokharel G. P. and Mariotti S.P., 2004. Global data on visual impairment in the year 2002, Bulletin of the World Health Organization, Geneva 1211, Switzerland.

2. An introduction to eyes and how they work, 2018. https://www.medicalnewstoday.com/articles/320608.php

3. Weinreb RN, Aung T, Medeiros FA, 2014. The pathophysiology and treatment of glaucoma: a review. JAMA.;311(18), 1901-11.

4. Cook C., Cockburn N., van der Merwe J. and Ehrlich R., 2009. Cataract and Glaucoma Case Detection for Vision 2020 Programs in Africa. An Evaluation of 6 Possible Screening Tests, Journal of Glaucoma,18(7), 557-562.

5. Five common glaucoma tests, 2017.https://www.glaucoma. org/glaucoma/diagnostic-tests.php

6. Mirnezami S. A., Rajaei Jafarabadi M. and Abrishami M., 2013. Temperature distribution simulation of the human eye exposed to LASER radiation. Journal of LASERs in medical sciences, 4(4), 175-81.

7. Fabiani C., Li Voti R., Rusciano D., Mutolo M. G. and Pescosolido N., 2016. Relationship between Corneal Temperature and Intraocular Pressure in Healthy Individuals: A Clinical Thermographic Analysis. Journal of ophthalmology, 2016, 3076031. doi:10.1155/2016/3076031
8. GabeltB. T. and Kaufman P. L.,2005. Changes in aqueous humour dynamics with age and glaucoma.,Elsevier Progress in Retinal and Eye Research, 24(5), 612-637.

9. Miller P. E., 2009. Structure and function of the eye, Slatter's Fundamentals of Veterinary Ophthalmology. St. Louis, Missouri, Elsevier.

10. NgE. Y. K., TanJ. H., Rajendra AcharyaU. and SuriJ. S., 2012. Human Eye Imaging and Modeling, London: CRC Press.

11. Static Fluid Pressure, http://hyperphysics.phyastr.gsu.edu/hbase/pflu.html.

12. Human Eye Model, https://grabcad.com/library/human-eye-model

13. Cvetkovic M., Poljak D. and Peratta A., 2008. Thermal modelling of the human eye exposed to laser radiation. $200816^{\text {th }}$ International Conference on Software, Telecommunications and Computer Networks, 16-20.

14. Narasimhan A. and Jha K.K., Bio-heat transfer simulation of square and circular array of retinal laser irradiation,Int. J. Numer. Meth. Biomed. Engng.,28(5), 547-559.

15. Liu X., Yao Y.F. and Xu X.Y., Application of Nd:YAP laser in dental pulp revascularization, 2017. Shanghai journal of Stomatology, 26(6), 628-632.

16. Murphy M.J. and Huang M.Y., 1994. Q-switched ruby laser treatment of benign pigmented lesions in Chinese skin. Annals of the Academy of Medicine, Singapore, 23, 60-6.

17. EvtuhovV. and Neeland J.K., 1967. Power Output and Efficiency of Continuous Ruby LASERs. Journal of Applied Physics, 38(10), 4051 - 4056.

18. PengQ., JuzenieneA., ChenJ., SvaasandL., Warloe T., Giercksky K.E. and MoanJ., 2008. LASERs in medicine, Reports on Progress in Physics,71(5).

19. Siham A. Kandela, 1991. LASER Physics in Medicine, ELHekima Publishing and Printing Establishment Bagdad.

20. Kaya Ball, 1995. LASERs the Perioperative Challenge, second Edition, Published in Nabcy L. Coon, US

21. M. Tkáčová, J. Živčák and P. Foffová, A Reference for Human Eye Surface Temperature Measurements in Diagnostic Process of Ophthalmologic Diseases, 2011,Proceedings of the 8th International Conference, Smolenice, Slovakia, 406-409. 